Besides defending the rationality of the operation, the author asserts that in exophthalmic goitre, as well as in ordinary large goitre, it will invariably diminish the size of the gland and remove in a large degree the danger of subsequent extirpation should such interference be afterwards necessary.

PATRICK.

Intradural Section of the Spinat Nerves for Neuralgia.

Robert Abbe, M.D., in the Boston Medical and Surgical Journal, Oct. Ist, I8g6, reports three cases in which parts of the posterior roots of the brachial plexus were divided or resected at their intradural origin from the cord for severe and persistent neuralgia. A fourth case in which the four lumbar posterior roots and one upper sacral were divided, is also reported from St. George's Hospital, London, operated on by Mr. Bennett. In all three was marked improvement afforded in the relief of pain, and Dr. Abbe's conclusions are epitomized as follows: $\frac{-}{4}$

"A comparatively new and interesting field of work is opened by these few cases.

"Thus far, even in weak patients, the operation has been devoid of risk.

"It is sound in theory, and has yielded enough results to show that it may become a meritorious operation.

"It should be resorted to early in cases of ascending neuritis which have heretofore been subjected to successive nerve-stretching and resection, and finally amputation, uniformly without benefit.

"The experimental and practical evidence shows that two additional roots higher up than the apparent origin of pain should be included.

"There ought to be no risk in severing the posterior roots of the third and fourth cervical, as well as those to the brachial plexus, simply because they supply the phrenic, inasmuch as that needs motor supply only, and at best it has the opposite phrenic in reserve."

SHIVELY.

Treatment of Refractory Neuralgia by Intradural Resection OF THE POSTERIOR ROOTS.

Dr. Chipault exhibited at the Academie de Médécine (Medical Week, Jan. 22d, r897) a patient who was operated upon for the relief of severe neuralgia in the right upper limb, by intradural resection of the eighth right posterior cervical root, the pain clearly and persistently manifesting itself in the domain of this nerve. The patient was completely cured, and inasmuch as the recovery had been maintained for two years, it may be considered as definite. No functional disturbance, either motor or sensory, followed the operation; hyperæsthesia persisted barely during twenty-four hours in the area supplied by the divided nerve.

Mitchell.

\title{
Resection of the Ulnar and Median Nerves for the Relief of Generalized Neuromata.
}

Dr. Pean showed at the Académie de Médécine (Medical Week, Jan. 22d, 1897) a man, twenty-five years of age, suffering from generalized neuromata, in whom Dr. P. had resected a large part of the median and ulnar nerves. This operation, as usual, was followed by complete paralysis and anæsthesia in the domain of the nerves; but movement and sensation were gradually restored. At the time of the exhibition the patient experienced no difficulty in the use of his arm, except a little in the thumb. This was ten months after the operation and there had been no recurrence. All the neturomata which existed on the forearm and in the supraclavicular region had become atrophied and disappeared after the operation.

Mitchell.

Animal Extracts in the Treatment of Menral Disfase. (Discus- 